Mesci, S, et al. International Journal of Science Letters. 2019. 1(1): 14-19.

\title{
Review
}

\section{The effect of ATP-binding cassette (ABC) transporters in human cancers}

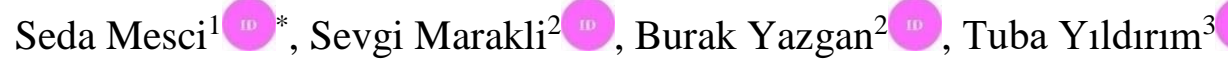 \\ ${ }^{1}$ Department of Medical Biochemistry, Faculty of Medicine, Hitit University, Çorum/Turkey \\ ${ }^{2}$ Department of Medical Services and Techniques, Sabuncuoğlu Serefeddin Health Services \\ Vocational School, Amasya University, Amasya/Turkey \\ ${ }^{3}$ Department of Biology, Faculty of Arts and Sciences, Amasya University, Amasya/Turkey
}

\begin{abstract}
Multi-drug resistance (MDR) can be defined as a negative effect on the drug-target relationships, decreasing in intracellular drug aggregation.

ABC (ATP-binding cassette) are popular transporter proteins in the development of MDR. ABC proteins in the cell membrane structure reduce the therapeutic efficacy and cause drug resistance in cancer patients. Resistance to chemotherapy is a remarkable and important issue in the treatment of cancer patients. These drug resistance proteins interfere with the drugs administered to patients, resulting in a decrease in bioavailability of these drugs and a reduction in their passage through the blood-brain barrier. $\mathrm{ABC}$ transporters are the largest family of transmembrane proteins with 8 subfamilies assigned from $A$ to $G$ based on sequence and structural homology. In this review, general information about $\mathrm{ABC}$ proteins is mentioned and the role of $\mathrm{ABC}$ proteins causing MDR in cancers is also discussed.
\end{abstract}

Article History Received 05.06.2019 Accepted 31.07.2019

\author{
Keywords \\ Cancer treatment, \\ ABC transporters, \\ Multi-drug resistance
}

\section{Introduction}

One of the major problems of clinical treatment methods in cancer patients is the improvement of resistance against to cancer drugs. Chemotherapy resistance leads to unsuccessful treatment in more than $90 \%$ of patients with metastatic cancer. Drug transport proteins of tumor character cause suppression of apoptosis, increase proliferation, change in drug-target interaction, drug inactivation and resistance to cytotoxic agents (Housman et al., 2014). The pharmacological mechanism is effective in reaching the drug to the target cell. Resistance causes pharmacological ineffectiveness of the drug in the cell mechanism (Leonessa and Clarke, 2003). Multiple drug resistance (MDR) reduces the effectiveness of

${ }^{1}$ Correspondence: sedamesci@gmail.com 
anticancer drugs and the likelihood of successful cancer chemotherapy. This leads to failure of chemotherapy, which is a major problem in cancer treatment (Pala Kara et al., 2013; Wang et al., 2014; Mansoori et al., 2017).

ABC (ATP-binding cassette) proteins are primary active carriers that are localized in the cell membrane and depend on ATP, which is responsible for transport of drugs and drug metabolites in the organism. The proteins is an ATP-dependent drug efflux pump with broad substrate specificity. It is responsible for decreasing drug accumulation in multidrug-resistant cells and often mediates the development of resistance to anticancer drugs. ABC transporter proteins prevent the accumulation of drugs in tumor tissue by expelling antineoplastic drugs from tumor cells and show low activity because of reduced accumulation of drugs at the target site ( Wang et al., 2014; Cort et al., 2016). This protein also functions as a transporter in the blood-brain barrier. During the uptake and excretion of molecules into the cell, major changes can occur in the membrane. Therefore, "cancer is a cell membrane disease" can be said (Erdamar et al., 2014).

ATP binding cassette proteins, P-glycoprotein (Pgp), which is the first member of the B subfamily, is particularly noteworthy (Boumendjel et al., 2009; Karva , 2014). The first ABC protein demonstrating the resistance to multiple natural product drugs used in the treatment of cancer is the $170 \mathrm{kDa}$ P-glycoprotein (MDR1) originally described in 1976. (Thoeringer et al., 2007; Sharom, 2008). Since this glycoprotein modulates membrane permeability against various drugs, the first letter of the word "permeability" is named with the letter "P" (Juliano and Ling et al., 1976). Permeability glycoprotein is expressed in the apical membranes of tissues such as the intestine, liver, blood-brain barrier, kidney, placenta and testes and contributes to intracellular drug deposition (Vasiliou et al., 2009; Tulsyan et al., 2016; Domenichini et al., 2019). Among the following the discovery of P-gp proteins, the family of proteins associated with multidrug resistance (MRP) was identified in 1992 and, unlike Pgp, exhibits an additional structural difference, TMDo (transmembrane domain zero) and Lo (lasso motif). at the N-terminus (Cole et al., 1998; Pala Kara et al., 2013).

A functional unit of these proteins typically consists of two cytoplasmic ATP binding domains (NBD, nucleotide-binding domain) and two transmembranal domains (TMDs) extending into the membrane bilayer. NBDs contain amino acid sequences called Walker A, Signature C and Walker B motifs that are required for ATP binding and hydrolysis (Figure 
1A). Walker A: encapsulates the phosphate chain of ATP; Walker B: coordinates a magnesium ion necessary for ATP hydrolysis and contributes to a stabilizing aspartate residue. The $\mathrm{ABC}$ image (motif $\mathrm{C}$ ) and other aromatic rings, $\mathrm{D}, \mathrm{H}, \mathrm{Q}$ motifs provide originality and high protection (Figure 1B) (Flanagan and Huber, 2007; Boumendjel et al., 2009; He et.al., 2019).
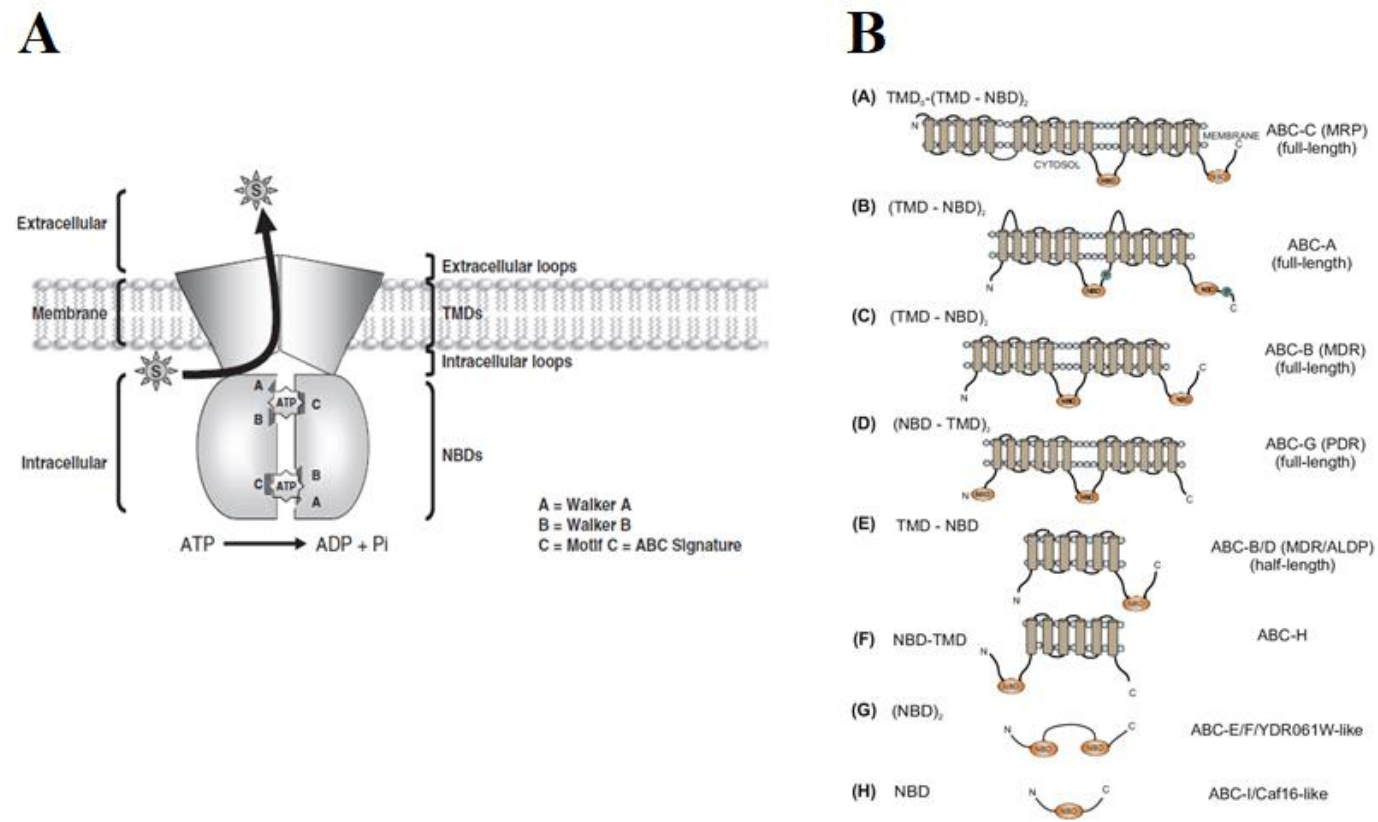

Figure 1. A.ABC transport structure; B. ABCA, ABCB, ABCC, ABCD, ABCE, ABCF, $\mathrm{ABCG}$ and $\mathrm{ABCH}$, transporter structures belonging to the $\mathrm{ABC}$ transporter family (Boumendjel et al., 2009; Baral, 2017).

$\mathrm{ABC}$ transporter proteins are a large family of proteins. This superfamily is represented by 61 genes in the human genome, dividing into 8 subfamilies based on gene structures, number and organization of domains (parts) and amino acid sequences (Figure 2) (Dean et al., 2001; Stavrovskaya and Stromskaya, 2008; He et.al., 2019). The proteins of the ABC carriers and the genes of these proteins are named in two different ways. For example, the first member of the $\mathrm{ABC}$ transporter family, ABCB1protein, is expressed as the MDR1 gene (Flanagan and Huber, 2007; Boumendjel et al., 2009). Multidrug resistance associated protein 3 also known as MRP3, encoded by the gene ABCC3, (ATP-binding cassette, subfamily C, member 3) (Ji et al., 2018). ABCC3, detected in the liver, intestine and adrenal gland cloned with human, rat and mouse, is found in the basolateral membranes of intrahepatic bile duct epithelial cells (cholangiocytes), hepatocytes surrounding portal pathways and intestinal epithelial cells. $\mathrm{ABCC} 3$ expression is higher in the colon than in the ileum. 
Furthermore, ABCC3 was found to be the most expressed carrier in the examined portions of the human intestine, except for the terminal ileum, where ABCB1 showed the highest expression (Boumendjel et al., 2009). ATP-binding cassette transporter 10 (ABCC10), also known as multidrug resistance protein 7 (MRP7) (Kathawala et al., 2014). A sample of ABCC10 protein expression in tissues has not yet available. Using reverse transcriptase polymerase chain reaction, $\mathrm{ABCC} 10$ transcripts were detected in most tissues reported at relatively higher levels in the pancreas, testes, colon, spinal cord, tonsils, lung, trachea and skin. Moderate expression was detected in the intestine ovary, uterus and placenta and liver (Boumendjel et al., 2009; Vasiliou et al., 2009; Domenichini et al., 2019). The ABCC11 gene encodes the multidrug resistance-associated protein 8 (MRP8) (Lang et al., 2018). Despite data conflicting with $\mathrm{ABCC} 11$ transcript expression in tissues, $\mathrm{ABCC} 11$ levels are expressed in a variety of human tissues including normal breast, ovary, lung, testis, kidney, liver, colon and brain (Boumendjel et al., 2009; Vasiliou et al., 2009; Domenichini et al., 2019; Ishiguro et al., 2019). In chemotherapy treatments, ABC transport proteins are valuable molecules because they are related to drug-target interactions. Therefore, there are many reports to investigate these proteins to improve cancer cure.

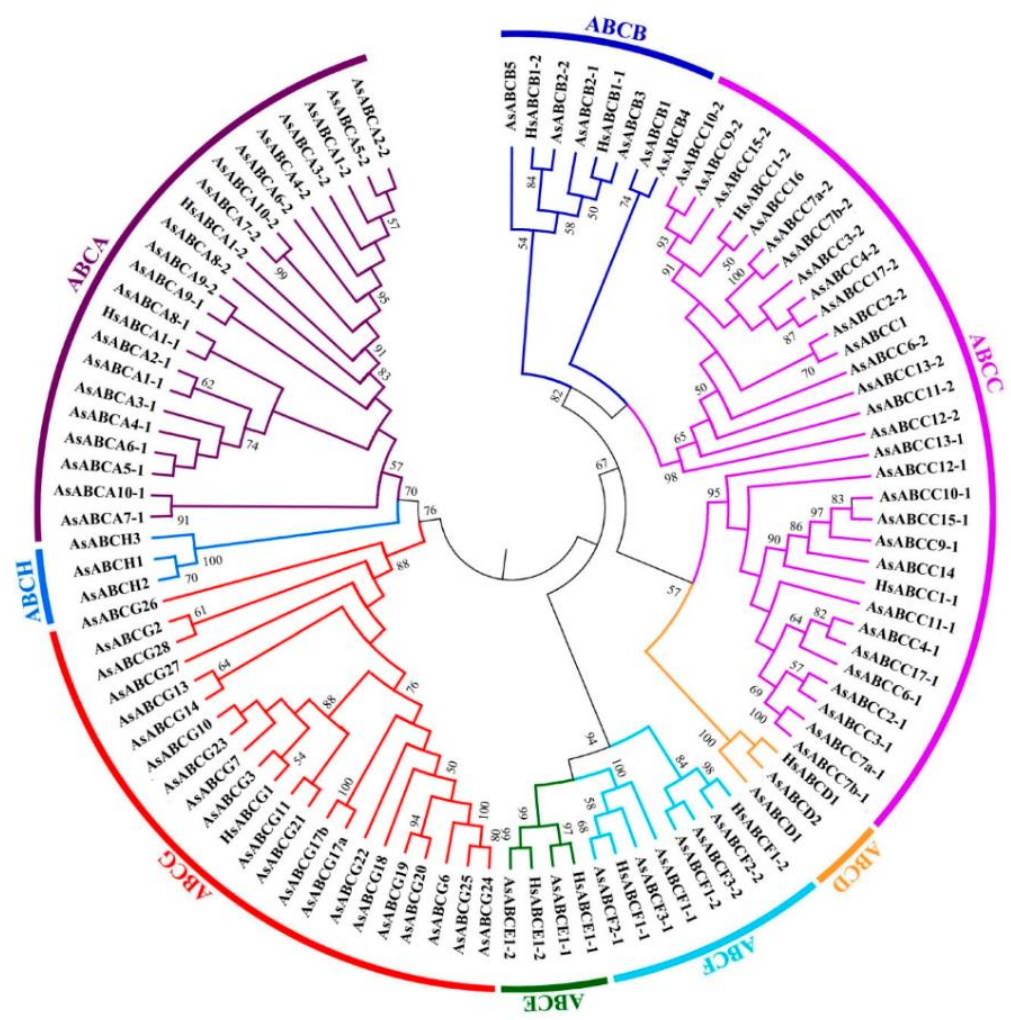

Figure 2. Eight different subfamilies (ABCA, ABCB, ABCC, ABCD, ABCE, ABCF, $\mathrm{ABCG}$ and $\mathrm{ABCH}$ ) belonging to the $\mathrm{ABC}$ trasnporter family (He et.al., 2019). 


\section{Conclusion}

World Health Organization reported that the most common causes of cancer are lung, breast, colon and prostate cancer. One of the main drawbacks of cancer treatments is MDR. $\mathrm{ABC}$ transporter proteins play important role in absorption, metabolism, distribution and excretion in excretory organs. Therefore, a more successful outcome for $A B C$ transporter inhibitors in cancer treatment, a more targeted ABC transporter approach should be applied which specific carrier plays an important role in a drug-target interactions.

\section{References}

Baral, B. 2017. Evolutionary trajectories of entomopathogenic fungi ABC transporters, Advances in Genetics, 98: 117-154.

Boumendjel, A., Boutonnat, J., Robert, J., 2009. ABC transporters and multidrug resistance. John Wiley \& Sons Inc, Hoboken, New Jersey.

Cole, S.P., Deeley, G.R., 1998. Multidrug resistance mediated by the ATP binding cassette transporter protein MRP, Bioessays, 20 (11):931-940.

Cort, A., Ozben, T., Saso, L., De Luca, C., Korkina, L. 2016. Redox control of multidrug resistance and its possible modulation by antioxidants, Oxidative Medicine and Cellular Longevity, http://dx.doi.org/10.1155/2016/4251912

Dean, M., Rzhetsky, A., Allikmets, R. 2001. The human ATP-binding cassette (ABC) transporter superfamily, Genome Research, 11(7):1156-1166.

Domenichini, A., Adamska, A., Falasca, M. 2019. ABC transporters as cancer drivers, potential functions in cancer development, Biochimica et Biophysica Acta-General Subjects, 1863(1): 52-60.

Flanagan, J.U., Huber, T. 2007. Structural evolution of the ABC transporter subfamily B, Evolutionary Bioinformatics, 3: 309-316.

Gupta, P., Zhang, Y. K., Zhang, X. Y., Wang, Y. J., Lu, K. W.,et al. Hall, T., 2018. Voruciclib, a potent CDK4/6 inhibitor, antagonizes ABCB1 and ABCG2-mediated multiDrug resistance in cancer cells, Cellular Physiology and Biochemistry, 45(4): 1515-1528.

He, Q., Yan, Z., Si, F., Zhou, Y., Fu, W., et al. 2019. ATP-binding cassette (ABC) transporter genes involved in pyrethroid resistance in the malaria vector anopheles sinensis: Genomewide identification, characteristics, phylogenetics, and expression profile, International Journal of Molecular Sciences, 20(6):1409.

Housman, G., Byler, S., Heerboth, S., Lapinska, K., Longacre, M., et al. 2014. Drug resistance in cancer, an overview, Cancers, 6(3): 1769-1792.

Erdamar, H., Hacievliyagil Kazanc1, F., Gök, S. 2014. Membrane biochemical changes in cancer, Journal of Clinical and Analytical Medicine, 5 (3): 430-438.

Ishiguro, J., Ito, H., Tsukamoto, M., Iwata, H., Nakagawa, H., \& Matsuo, K. et al. 2019. A functional single nucleotide polymorphism in ABCC11, rs17822931, is associated with the risk of breast cancer in Japanese, Carcinogenesis, 40(4): 537-543.

Ji, J. Z., Tai, T., Huang, B. B., Gu, T. T., Mi, Q. Y., \& Xie, H. G., 2018. Mrp3 transports clopidogrel acyl glucuronide from the hepatocytes into blood, Drug Metabolism and Disposition, 46(2): 151-154. 
Juliano, R.L., Ling, V. A. 1976. Surface glycoprotein modulating drug permeability in Chinese hamster ovary cell mutants, Biochimica et Biophysica, 455:152-162.

Karva, S., 2014. The role of ABC transporters in anticancer drug transport, Turkish Journal of Biology, 38: 800-805.

Kathawala, R. J., Wang, Y. J., Ashby, C. R., Jr., Chen, Z. S. 2014. Recent advances regarding the role of $\mathrm{ABC}$ subfamily $\mathrm{C}$ member 10 (ABCC10) in the efflux of antitumor drugs, Chinese journal of cancer, 33(5): 223-230.

Lang Z, Wu Y, Pan X, Qu G, Zhang T. 2018. Study of differential gene expression between invasive multifocal/multicentric and unifocal breast cancer, JBUON, 23(1): 134-142.

Leonessa F., Clarke, R., 2003. ATP binding cassette transporters and drug resistance in breast cancer, Endocrine-Related Cancer, 10: 43-73.

Mansoori, B., Mohammadi, A., Davudian, S., Shirjang, S., Baradaran, B. 2017. The different mechanisms of cancer drug resistance: A brief review, Advanced Pharmaceutical Bulletin, 7(3): 339-348.

Pala Kara, Z., Öztürk, N., Öztürk, D., Okyar, A. 2013. ABC taşıyıcı proteinleri, sirkadiyan ritimler ve cinsiyete bağlı farklılıklar, Marmara Üniversitesi Sağlık Bilimleri Enstitüsü Dergisi, 3(1):1-13.

Stavrovskaya, A.A., Stromskaya, T.P., 2008.Transport proteins of the ABC family and multidrug resistance of tumor cells, The Monthly Journal Biochemistry. (Moscow), 73:592-604.

Sharom, F.J., 2008. ABC multidrug transporters, structure, function and role in chemoresistance, Pharmacogenomics, 9(1):105-127.

Thoeringer, C. K., Wultsch, T., Shahbazian, A., Painsipp, E., \& Holzer, P. 2007. Multidrugresistance gene 1-type p-glycoprotein (MDR1 p-gp) inhibition by tariquidar impacts on neuroendocrine and behavioral processing of stress, Psychoneuroendocrinology, 32(810):1028-1040. 